\title{
Understanding Solid Electrolyte Interphase Nucleation and Growth on Lithium Metal Surfaces
}

\author{
Stefany Angarita-Gomez (D) and Perla B. Balbuena * (D) \\ Department of Chemical Engineering, Texas A\&M University, College Station, TX 77843, USA; \\ mariste_9428@tamu.edu \\ * Correspondence: balbuena@tamu.edu
}

Citation: Angarita-Gomez, S.;

Balbuena, P.B. Understanding Solid Electrolyte Interphase Nucleation and Growth on Lithium Metal Surfaces. Batteries 2021, 7, 73. https://doi.org/ $10.3390 /$ batteries7040073

Academic Editor: Wonbong Choi

Received: 2 August 2021

Accepted: 26 October 2021

Published: 2 November 2021

Publisher's Note: MDPI stays neutral with regard to jurisdictional claims in published maps and institutional affiliations.

Copyright: (C) 2021 by the authors. Licensee MDPI, Basel, Switzerland. This article is an open access article distributed under the terms and conditions of the Creative Commons Attribution (CC BY) license (https:// creativecommons.org/licenses/by/ $4.0 /)$.

\begin{abstract}
Experiments and theory are needed to decode the exact structure and distribution of components of a passivation layer formed at the anode surface of Li metal batteries, known as the Solid Electrolyte Interphase (SEI). Due to the inherent dynamic behavior as well as the lithium reactivity, the SEI structure and its growth mechanisms are still unclear. This study uses molecular simulation and computational chemistry tools to investigate the initial nucleation and growth dynamics of $\mathrm{LiOH}$ and $\mathrm{Li}_{2} \mathrm{O}$ that provide us with thermodynamics and structural information about the nucleating clusters of each species. Following the most favorable pathways for the addition of each of the components to a given nascent SEI cluster reveals their preferential nucleation mechanisms and illustrates different degrees of crystallinity and electron density distribution that are useful to understand ionic transport through SEI blocks.
\end{abstract}

Keywords: density functional theory; ab initio molecular dynamics; molecular electrostatic potential; passivation layer; nucleation and growth

\section{Introduction}

As modern society shifts apart from the use of fossil fuels and towards renewable sources, the improvement and development of energy storage devices become of great importance. Lithium metal is one of the best anode options due to its high theoretical capacity and negative electrochemical potential [1,2]. For next generation batteries, the use of Lithium metal anodes is crucial, especially for energy storage applications such as electric vehicles [3-6]. Nonetheless, issues related to poor cyclability and safety concerns related to dendrite growth and to unstable SEI formation have kept lithium metal anodes away from massive implementation [7].

Several strategies implemented to control dendrite growth such as electrolyte additives [8-10], artificial SEI layers [11,12], high salt concentration electrolytes, and others have been studied to create a dendrite-free battery [13-16]. An important conclusion from these analyses is that ion diffusion in the electrolyte and through the SEI nucleating on the metal may be key factors on regulating Li nucleation and growth [17].

The formation of a passivating layer is a hot research topic; the SEI model was first introduced by Peled in 1979 [18,19]. This SEI layer forms instantaneously as soon as the $\mathrm{Li}$ metal is exposed to the environment or in contact with the electrolyte due to $\mathrm{Li}$ metal reactivity and electrolyte instability. An SEI layer may consist of a solid or mixed solid-polymer-liquid product from the reaction between the Li metal slab and electrolytes. An ideal SEI should have Li ionic conductivity but electron blocking capabilities, thus preventing further electrolyte decomposition and parasitic reactions [20]. In addition, other properties such as high elastic strength are useful to mechanically suppress dendrites, along with proper thickness while being a compact structure [21].

Many electrolytes have been tested with Li metal anodes to improve both the efficiency and stability or to promote the formation of the desired SEI [13,14,22-24]. The presence of multicomponent electrolytes and the high reactivity of lithium metal anodes lead to a wide 
variety of $\mathrm{SEI}$ components including $\mathrm{Li}_{2} \mathrm{O}, \mathrm{LiOH}, \mathrm{LiF}$, and $\mathrm{Li}_{2} \mathrm{CO}_{3}$, along with organic and inorganic fragments and polymers. The SEI composition and structure strongly depend on the electrolyte components: solvents, salts, and additives [25-30]. Various aspects of the SEI have been studied such as its formation mechanisms [21,31-37] and the passivation effects that SEI components exert on the Li metal [20,38,39]. Additionally, the formation of stable SEI with fluorinated layers was suggested to prolong the stability of Li metal batteries by regulating Li deposition [22,40-43]. Several experimental and theoretical attempts have been performed to decode SEI structure and composition, but due to its strongly evolving behavior, as well as to the lithium's reactivity, such decoding is not yet accomplished [35,44-48].

The SEI's chemistry and morphology may affect its properties and the Li growth mechanisms [49,50]. Although recent work with improved experimental techniques can provide more information about the SEI [51], understanding of its nucleation remains unclear. Crystalline and amorphous SEI components [52] have been found in different electrolytes studied using pair distribution function (PDF) and X-ray diffraction (XRD) techniques [53] as well as cryoelectron microscopy (cryo-EM) [54] and cryogenic transmission electron microscopy (cryo-TEM) [50], emphasizing the importance of understanding the SEI structure and its correlation with electrolyte composition.

Because SEI nucleation mechanisms can determine SEI evolution and properties, here, we investigate the initial nucleation and growth dynamics of $\mathrm{LiOH}$ and $\mathrm{Li}_{2} \mathrm{O}$ clusters and analyze the associated energetics and structural SEI nucleation information for these components. Two different mechanisms are studied: molecular addition and fragment reduction. The molecular addition aims to understand the formation energies and structures of SEI nanoclusters that were already formed SEI molecules at or near the interface are added to grow larger SEI clusters. Fragment reduction simulates the reduction of fragments dissociated from solvent or anion molecules over a Li metal cluster. The Li metal cluster is representative of an inhomogeneous plating on the electrode surface. A molecule is surrounded by the molecular electrostatic potential (ESP) that is an electrical cloud created by the molecule's electrons and nuclei [55]. The ESP at a point $p(x, y, z)$ in the vicinity of a molecule can be defined as a force acting on a positive test charge located at point $p$. The calculated ESP surface of the Li cluster displays attractive and repulsive regions which are used to determine the possible sites where radicals or radical anions may attach during SEI nucleation. The obtained SEI nuclei geometries and morphologies are compared to those obtained in ab initio molecular dynamics (AIMD) simulations of precursor decomposition on a Li surface.

\section{Results and Discussion}

\subsection{Growth of Lithium Hydroxide SEI Nuclei by Molecular Addition}

The formation of $\mathrm{LiOH}$ molecules close to the surface has been observed in electrolytes with trace concentrations of water. Water-in-salt electrolytes were recently studied to identify the role of water in electrolyte decomposition. In these studies, the strong solvation formed around $\mathrm{Li}^{+}$by the water molecules causes the $\left.\left[\mathrm{Li}\left(\mathrm{H}_{2} \mathrm{O}\right)_{2 \mathrm{x}}\right)\right]^{+}$cation to be a 'soft' cation that, approaching the metal surface, can lead to the formation of $\mathrm{LiOH}$ by the cleavage of the $\mathrm{O}-\mathrm{H}$ bond in the water molecules [56]. $\mathrm{LiOH}$ has also been detected as a component of native SEIs as a result of exposure of Li metal to the environment [20]. Figure 1 shows the growth of $\mathrm{LiOH}$ by the molecular addition mechanism. Assuming that the first $\mathrm{LiOH}$ molecule is formed in the electrolyte near the Li surface, the location of ESP surfaces are used to determine the most preferred route/location where the next $\mathrm{LiOH}$ molecules will be added to the SEI LiOH nuclei. The electrostatic potential is calculated by the integration of the electronic density of a given cluster or molecule. Orange on the ESP plots indicates negative values on the isosurface, an attractive behavior for the Li-ion in the $\mathrm{LiOH}$ molecule and a repulsive one on the $\mathrm{OH}$ anion. This characteristic on the ESP plots helps to narrow down the possible growth structures and predicts the next deposition site of one $\mathrm{LiOH}$ molecule. 


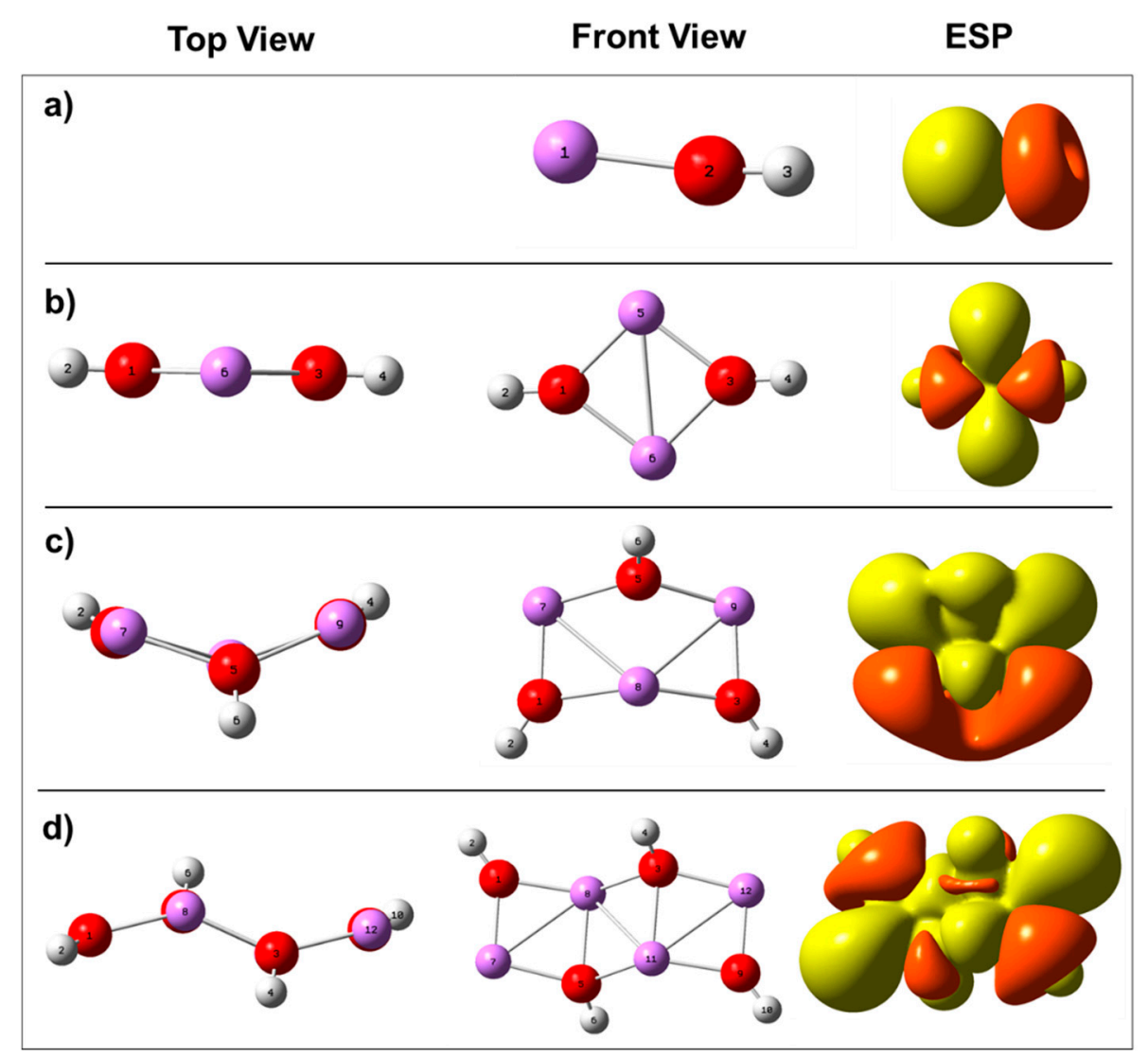

Figure 1. Optimized SEI nanoclusters after sequential addition of LiOH, structure (left) top view, (center) front view, and the corresponding ESP (right). (a) 1 molecule of $\mathrm{LiOH}$; (b) 2 molecules of $\mathrm{LiOH}$; (c) 3 molecules of LiOH; (d) 4 molecules of $\mathrm{LiOH}$. Isosurface value of 0.03 a.u. Orange is negative and yellow is positive. Color code: Lithium (Purple), Oxygen (red), and Hydrogen (white).

The ESP shown on the right side of Figure 1 highlights that each sequential addition of $\mathrm{LiOH}$ produces a symmetric cluster with positive and negative regions characteristic of the interactions between ion and dipole forces. Although not perfectly planar, the evolution of the structures in Figure 1 resembles the formation of a monolayer of $\mathrm{LiOH}$ which may lay almost flat on top of a surface by the fourth addition (Figure 1d). Figure 2 showcases the beginning of nanocluster formation where the structure in Figure 1d evolves to a 3D structure from the fifth molecule addition (Figure 2a). By the time it reaches $10 \mathrm{LiOH}$ molecules, the nanocluster resembles a bilayer of $5 \mathrm{LiOH}$ molecules each; these layers can be identified on the side view in Figure 2f. All the structures obtained and optimized follow an energetically favorable trend. Each change in the Free Energy of formation shown in Figure 3 illustrates the sequentially favorable addition of each $\mathrm{LiOH}$ molecule from 1 to 10 . Free energy changes of formation $\left(\Delta G_{f}(n)\right)$ shown in Figure 3 were calculated using Equation (1), where $\Delta G(n)$ is the free energy of the SEI cluster of size $n$ and $\Delta G_{L i O H}$ is the free energy of one $\mathrm{LiOH}$ molecule:

$$
\Delta G_{f}(n)=\Delta G(n)-\left[\Delta G(n-1)+\Delta G_{L i O H}\right]
$$




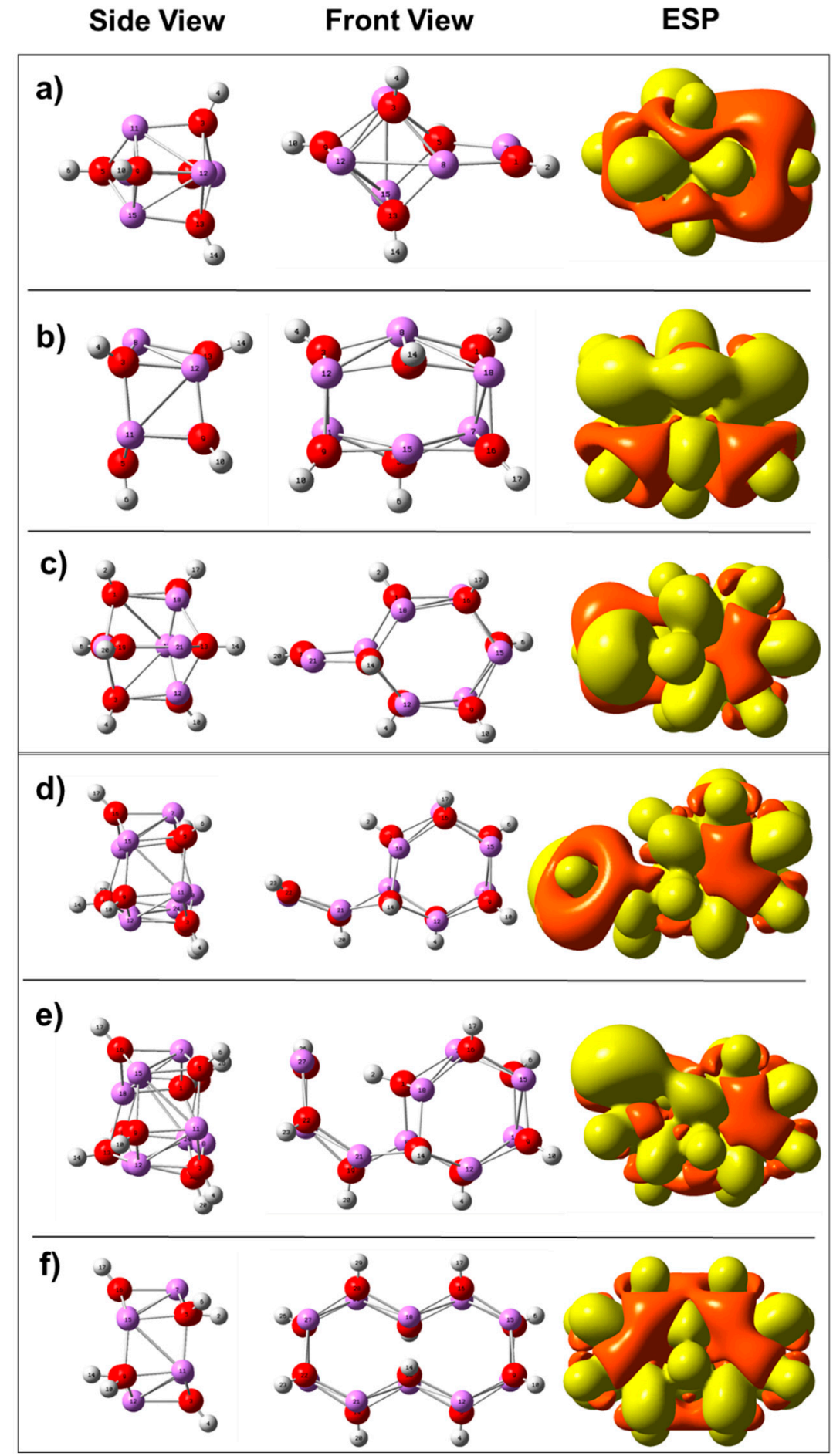

Figure 2. Optimized SEI nanoclusters after sequential addition of of $\mathrm{LiOH}$, structure (left) side view, (center) front view, and corresponding ESP (right). (a) 5 molecules of $\mathrm{LiOH}$; (b) 6 molecules of LiOH; (c) 7 molecules of LiOH; (d) 8 molecules of LiOH; (e) 9 molecules of $\mathrm{LiOH}$; (f) 10 molecules of LiOH. Isosurface value of 0.03 a.u. Orange is negative and yellow is positive. Color code as Figure 1.

The ESP surfaces also reveal how a Li-ion may travel through such nascent structures. The orange regions would tend to attract Li-ions and could act as channels for Li diffusion, whereas the yellow regions may promote a knock-off transport mechanism. Moreover, note that electric field gradients may change the locations of these regions, as shown in previous work [57], thus defining alternative diffusion pathways. 


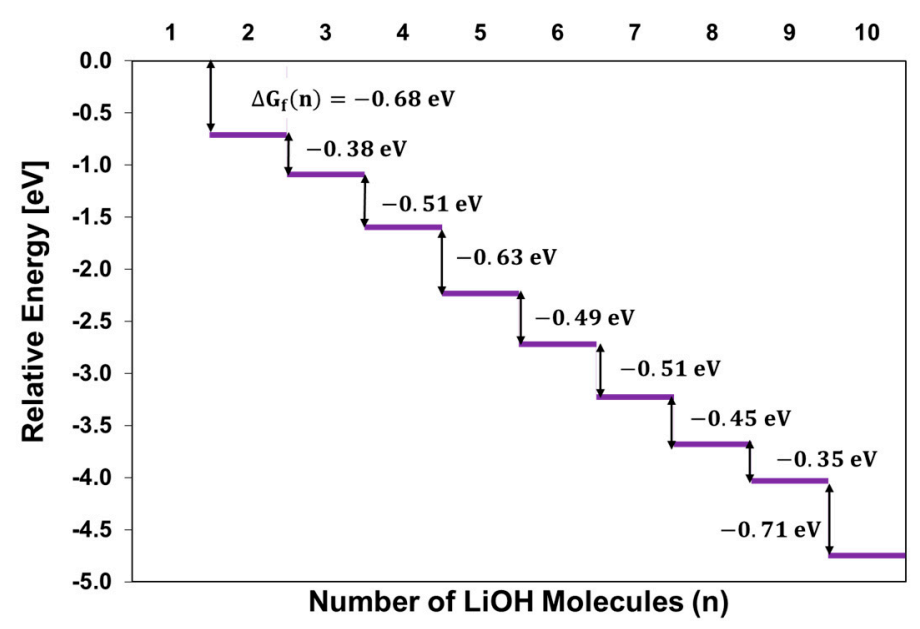

Figure 3. Calculated formation energy profile of $\mathrm{LiOH}$ nanocluster sizes from 1 to 10 molecules.

\subsection{Growth of SEI Nuclei by Fragment Reduction}

\subsubsection{Lithium Hydroxide}

Figure 4 shows an alternative nucleation route, via the addition of an $\mathrm{OH}$ radical that oxidizes the neutral $\mathrm{Li}_{6}$ nanocluster and forms $\mathrm{LiOH}$. The main finding in this fragmental growth mechanism is the interaction that the $\mathrm{OH}^{-}$radical has with $\mathrm{Li}$ metal atoms. This growth mechanism would be consistent with the addition of $\mathrm{OH}$ radicals formed by electrolyte side reactions to the Li metal surface. Every $\mathrm{OH}$ fragment interacts with three lithium metal atoms that are initially equidistant between them when $\mathrm{OH}$ has added the three $\mathrm{Li}$ atoms and $\mathrm{OH}$ interact, forming a triangular pyramid (Figure 4a). As more $\mathrm{OH}$ fragments are added, the initial Li cluster becomes separated. However, the ion-dipole $\mathrm{LiOH}$ molecules formed to connect via the initial $\mathrm{Li}$ atoms (Figure $4 \mathrm{~b}-\mathrm{d}$ ). The ESP shown in Figure 4 illustrates the electrostatic interaction behavior of the $\mathrm{OH}$ fragment with the $\mathrm{Li}$ metal cluster. An example is Figure $4 \mathrm{~b}$,d: When the $\mathrm{OH}$ is interacting with only two $\mathrm{Li}$ atoms, there is a large orange area in the ESP, indicating negative values on the isosurface and attractive behavior for incorporation of an additional Li-ion. The free energy profile is shown in Figure S1a.

Figure S1b shows the relative Gibbs Free Energy of formation for the addition of $\mathrm{OH}$ to the Li metal cluster and highlights the favorable addition of the $\mathrm{OH}$ to the metal cluster even in the presence of extra negative charge on the metal cluster surface. Each $\mathrm{OH}$ added to the metal cluster interacts with three Li metal atoms, and the addition is favorable.

To test the calculated structures, we carried out AIMD simulations where $\mathrm{LiOH}$ was generated by water dissociation and reaction on a Li surface. Figure 5 shows snapshots of an AIMD study in which $\mathrm{H}_{2} \mathrm{O}$ molecules are placed on top of a lithium metal surface. After 80 ps of reaction at $330 \mathrm{~K}$, the system was progressively cooled by lowering $10 \mathrm{~K}$ every 5 ps. The cooling rate is shown in Figure $5 \mathrm{~d}$. Water molecules react with the lithium metal and form $\mathrm{LiOH}$ and $\mathrm{H}_{2}$ as shown in Figure 5b. Figure 5c illustrates similarities of the $\mathrm{OH}-\mathrm{Li}$ interaction between the AIMD water-induced growth of $\mathrm{LiOH}$ on Li metal surface and the $\mathrm{OH}$ addition to Li clusters obtained with quantum chemistry calculations in small clusters shown in Figure 4. After the cooling process, the structure becomes more organized as shown in the increasing intensity of the main peak (at $\sim 1.97 \AA$ ) in the $\mathrm{g}_{\mathrm{LiO}}(\mathrm{r})$ radial distribution function in Figure $5 \mathrm{e}$. This distance is in the range of the Li-O distances in the cluster shown in Figure 4 (1.89 to $1.98 \AA$ ). Figure S2 shows the similarities between the LiOH crystalline structure and the AIMD structure after the cooling process, the most common distances between $\mathrm{Li}-\mathrm{O}, \mathrm{Li}-\mathrm{H}$, and $\mathrm{O}-\mathrm{H}$ are similar to the ones found in the crystalline structure. 


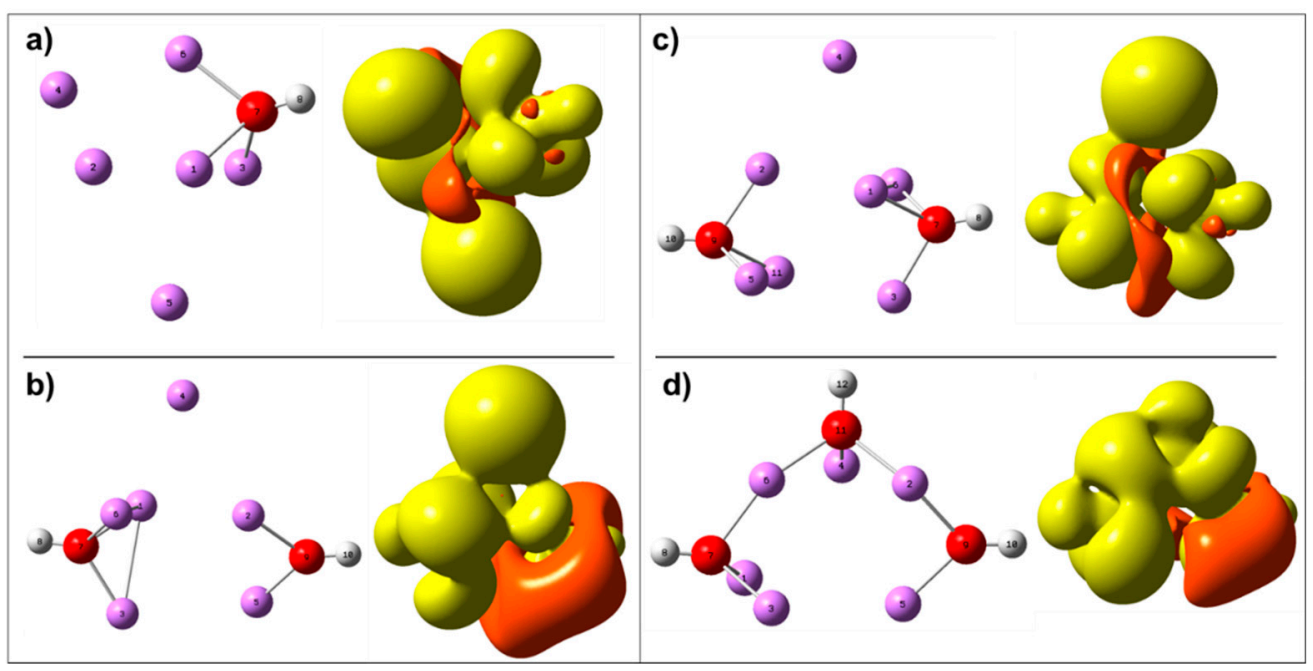

Figure 4. Calculated formation energy profile of $\mathrm{LiOH}$ nanocluster, fragment addition to lithium metal cluster. The net total charge in the cluster including the $\mathrm{OH}$ fragment is zero. (a) first addition of $\mathrm{OH}$ to the Li metal cluster; (b) second addition of $\mathrm{OH}$ to structure shown in (a); (c) Addition of one Li metal atom to structure in b); (d)Third addition of $\mathrm{OH}$ to structure shown in (b). Color code as Figure 1.
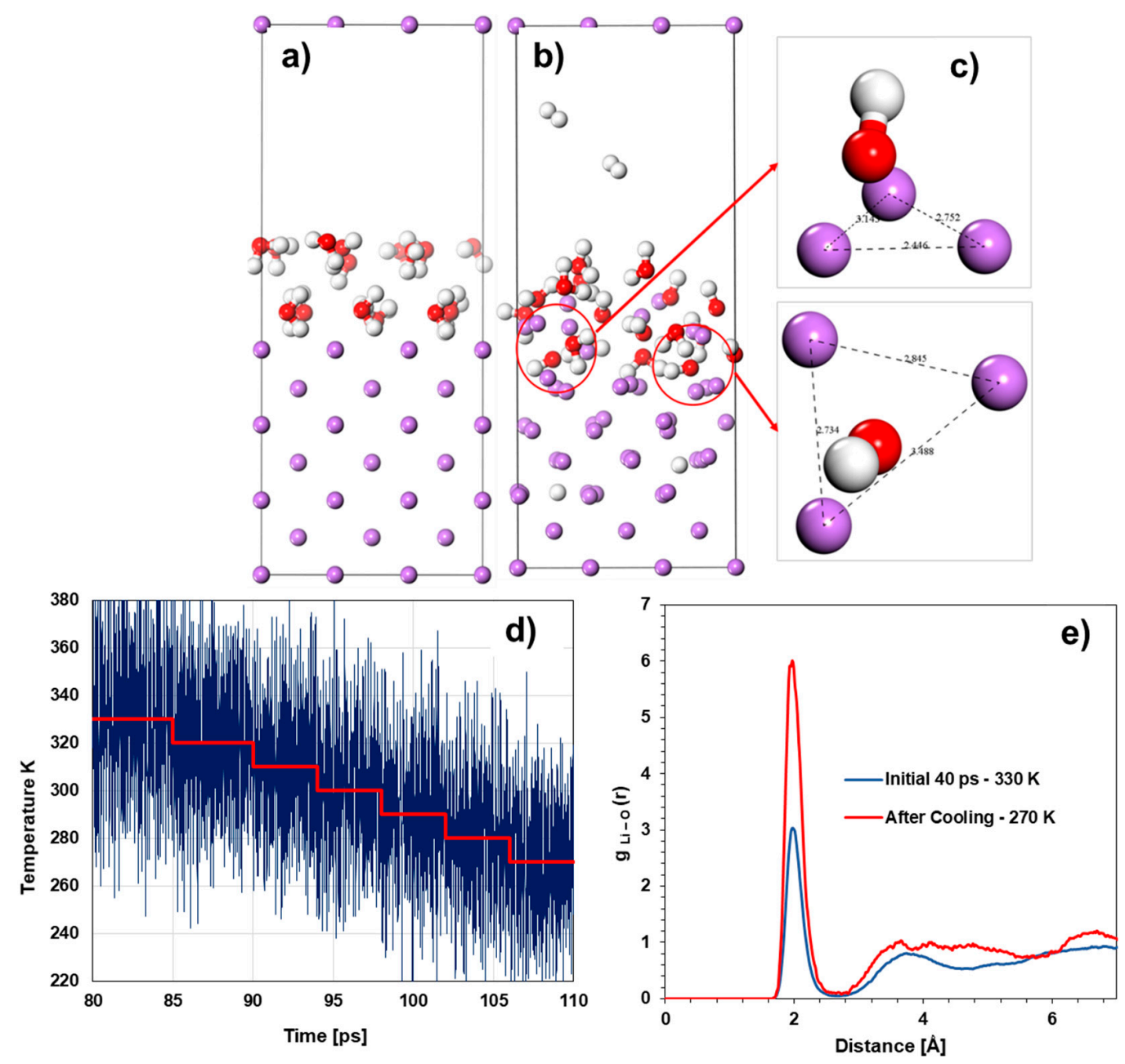

Figure 5. (a) Initial structure with two monolayers of water on top of (100) Lithium metal slab. (b) Snapshot at 50 ps of AIMD simulation at $330 \mathrm{~K}$. (c) LiOH nanocluster formation with similar characteristics to the cluster calculation (Figure 4). (d) Cooling rate to take the cell from $330 \mathrm{~K}$ to $270 \mathrm{~K}$. (e) Radial distribution function (Lithium-Oxygen) comparison in early stages of the dynamic process and $330 \mathrm{~K}$ and after cooling at $270 \mathrm{~K}$. 


\subsubsection{Lithium Oxide}

Oxygen atoms are generated by the decomposition of products of the reduction of organic carbonates such as ethylene carbonate (EC), propylene carbonate (PC), fluoroethylene carbonate (FEC), but also from anions or other additives, and Li oxides are also very often found as native layers on $\mathrm{Li}$ surfaces. The sequential addition of oxygen atoms to the $\mathrm{Li}_{6}$ metal cluster, along with its ESP, is shown in Figure S3. The structure of a $\mathrm{Li}_{2} \mathrm{O}$ cluster obtained after the sequential addition of oxygen atoms to $\mathrm{Li}_{6}$ reveals interesting similarities with the crystalline bulk structure. Figure 6 shows $\mathrm{Li}_{2} \mathrm{O}$ cluster when added oxygen atoms reach the stoichiometric ratio.

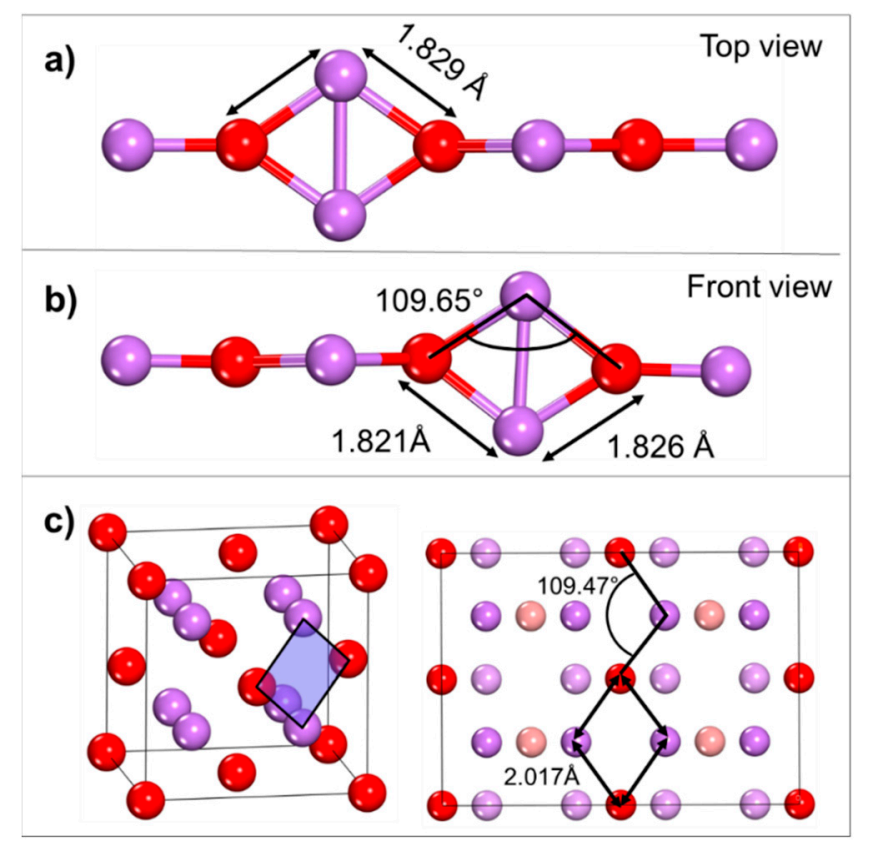

Figure 6. $\mathrm{Li}_{2} \mathrm{O}$ cluster formed by the sequential addition of Oxygen atoms to $\mathrm{Li}_{6}$ Metal cluster. (a) Top view. (b) Front view. (c) Unit cell of crystalline $\mathrm{Li}_{2} \mathrm{O}$ (left) and (110) facet (right) for comparison of measurements. Color code as Figure 1.

The $\mathrm{Li}_{6}$ metal cluster structure becomes completely modified throughout this process, and the cluster formed has similar atomic distances and angles to the crystalline structure of the $\mathrm{Li}_{2} \mathrm{O}$ (110) facet. Additional studies performed in a larger Li metal cluster (15 atoms) shown in Figure 7 highlight the preferential formation site of $\mathrm{Li}_{2} \mathrm{O}$. Figure $7 \mathrm{a}-\mathrm{d}$ show the optimized structures for the initial structure until the addition of the third oxygen atom. For each new oxygen addition, four to five different sites were tested (not necessarily closer to the previously deposited atoms); however, the first three lowest energy oxygen atoms were found located closer to each other (Figure $7 \mathrm{~d}$ ). In the next addition, shown in Figure $7 \mathrm{e}$, the top of the cluster rearranges creating a $\mathrm{Li}_{2} \mathrm{O}$ cluster separated that the $\mathrm{Li}$ metal region, and the fourth $\mathrm{O}$ addition takes place in that $\mathrm{Li}$ metal region. In the subsequent additions (Figure 7f,g), a new $\mathrm{Li}_{2} \mathrm{O}$ cluster starts to be formed following new $\mathrm{O}$ incorporations, and in Figure $7 \mathrm{~h}$, we observe that the top and bottom $\mathrm{Li}_{2} \mathrm{O}$ clusters try to rearrange in a unified structure. Note also the ESP diagrams with alternating positive and negative regions. As discussed with $\mathrm{LiOH}$, as the SEI is being formed by the fusion of nascent clusters (in this case $\mathrm{Li}_{2} \mathrm{O}$ ), the ESP provides an idea about the possible $\mathrm{Li}$-ion migration patterns. Looking at Figure $7 \mathrm{~b}-\mathrm{h}$, these alternating positive and negative regions may offer a favorable migration channel via hopping or knock-off mechanisms. From Figure 7, the presence of large yellow regions suggests that the Li-ion may migrate easily or become reduced at the periphery of these clusters. However, as the oxide forms, the orange alternate with yellow regions, and that describes a more complex surface for ion migration. Given that the yellow regions are still present in the inner part of the nascent $\mathrm{Li}_{2} \mathrm{O}$ clusters 
(see for example Figure 7f), it is difficult to think that $\mathrm{Li}$ ions will migrate through vacancies inside the clusters. Instead, it is more plausible that ionic migration takes place through the surface of the nascent clusters. This also suggests that the morphology of an optimum SEI layer should be one where small clusters are dispersed in a matrix, allowing ionic migration through their surfaces.

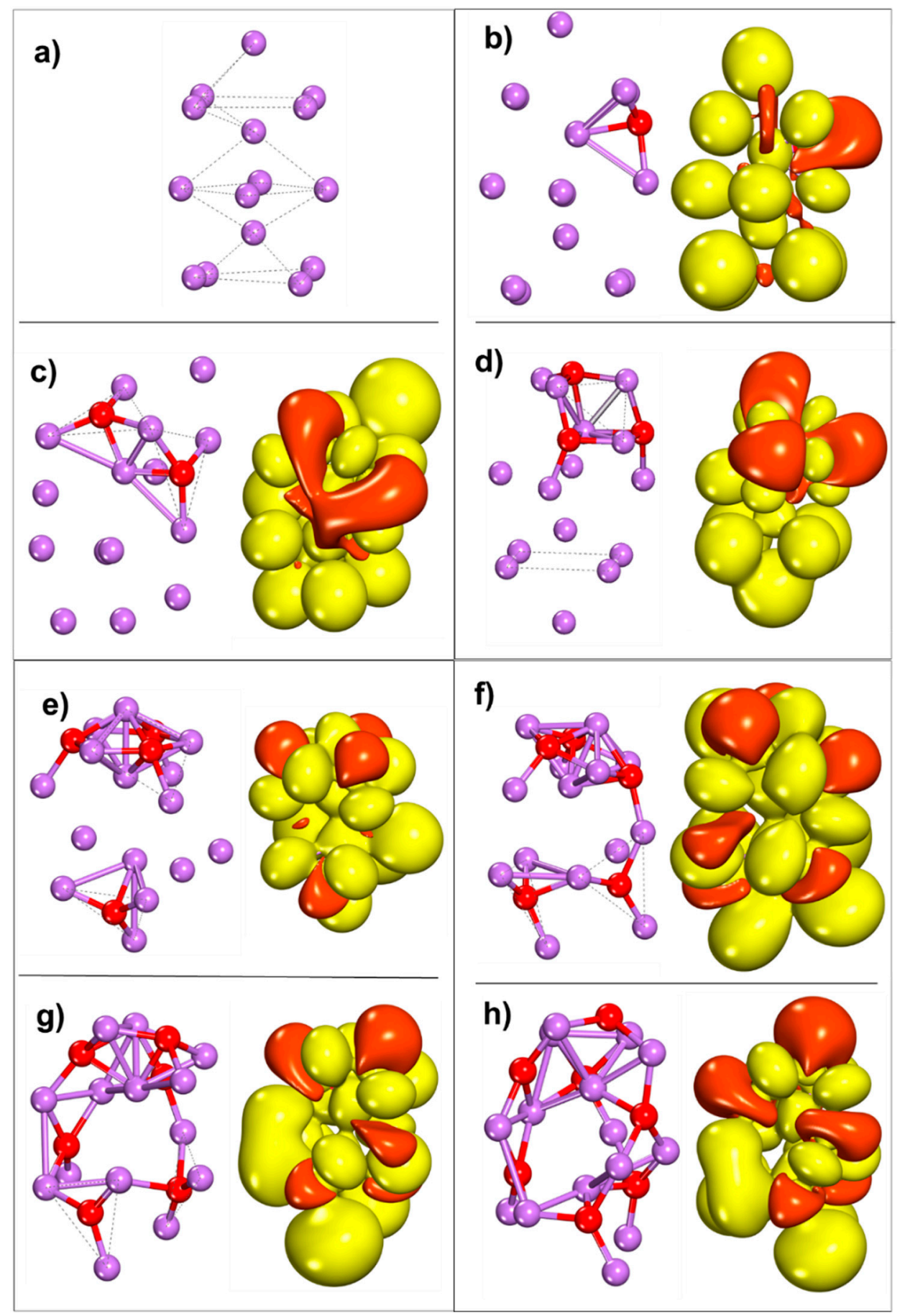

Figure 7. Optimized $\mathrm{Li}_{2} \mathrm{O}$ nanoclusters after Successive Oxygen additions to $\mathrm{Li}_{15}$ metal cluster structure (left) and corresponding ESP (right). Images ( $\mathbf{a}-\mathbf{h})$ showcases the initial $\mathrm{Li}_{15}$ nanocluster and the structures after each addition of oxygen until seven total Oxygen atoms added respectively. Isosurface value of 0.03 a.u. Orange is negative and yellow is positive. 
As with $\mathrm{LiOH}$, we performed AIMD simulations to investigate the structure that would be formed by an SEI reaction. Figure 8 depicts the geometries obtained when $\mathrm{O}_{2}$ is in contact with a $\mathrm{Li}$ metal surface. The distances and angles found after Li oxidation and formation of a $\mathrm{Li}_{2} \mathrm{O}$ surface film are similar to $\mathrm{Li}_{2} \mathrm{O}$ clusters obtained with quantum chemistry calculations shown in Figure 6.

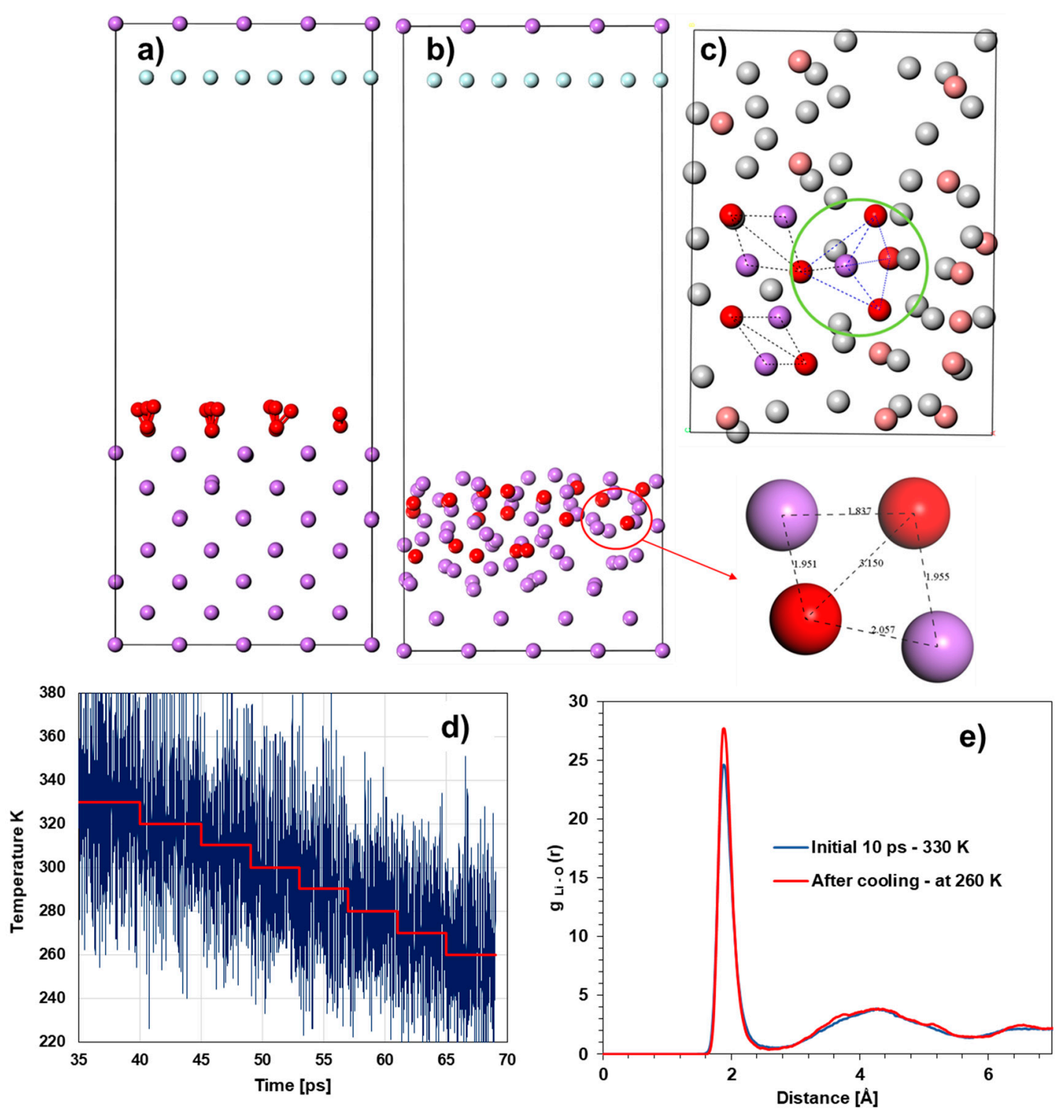

Figure 8. (a) Side view of $10 \mathrm{O}_{2}$ molecules lying parallel on top of (100) Lithium metal slab. (b) Snapshot of AIMD simulation at $40 \mathrm{ps}$ at $330 \mathrm{~K}$. (c) Highlight of $\mathrm{Li}_{2} \mathrm{O}$ nanocluster formation with Scheme $330 \mathrm{~K}$ to $260 \mathrm{~K}$. (d) Cooling rate to take the cell from $330 \mathrm{~K}$ to $260 \mathrm{~K}$. (e) Radial distribution function (Lithium-Oxygen) comparison in early stages of the dynamic process and $330 \mathrm{~K}$ and after cooling at $260 \mathrm{~K}$. Color code: Lithium (purple), Oxygen (red), Light grey and pink in (c) are lithium and oxygen atoms, respectively, located in the background.

The AIMD simulations were carried out for $35 \mathrm{ps}$ at $330 \mathrm{~K}$. After this time, the system was progressively cooled at the same cooling rate used for the $\mathrm{LiOH}$ system, as shown in Figure 8d. After the cooling process, the structure becomes more organized. Although the structural change is small compared to that of $\mathrm{LiOH}$, the red line in Figure $8 \mathrm{e}$ and the increasing intensity of the main peak in the radial distribution function can be observed. Comparison with the crystalline structure is highlighted in Figure S4. The main interactions between $\mathrm{Li}$ and $\mathrm{O}$ and between $\mathrm{O}$ and $\mathrm{O}$ are reasonably reproduced by the AIMD structure, which follows similar patterns as the clusters in Figures 6 and 7. The comparison of Figures 
$5 e$ and 8e shows a different extent of rearrangement after the cooling process. This is credited to the differences in crystalline structure and bonding. $\mathrm{LiOH}$ has been defined as being at the intersection between ionic bonding and hydrogen bonding [58], where the $\mathrm{H}$-bonding characteristics are temperature-dependent, in contrast to the case of a pure ionic bonding crystal such as $\mathrm{Li}_{2} \mathrm{O}$. Thus, the $\mathrm{T}$-dependent behavior of $\mathrm{H}$-bonding explains the substantial change in the radial distribution function shown in Figure $5 \mathrm{e}$, in contrast to the almost unchanged structure of $\mathrm{Li}_{2} \mathrm{O}$ (Figure 8e) under the same cooling process. When the cell cools down the $\mathrm{OH}$ fragment and residual water molecules become less mobile and more organized resulting in the peak of the RDF increasing. In $\mathrm{Li}_{2} \mathrm{O}$ the $\mathrm{Li}-\mathrm{O}$ bonds are more rigid and the change after cooling is much less significant.

The advantage of analyzing in parallel the cluster calculations of the growing structures and those of dynamic (amorphous) structures generated in AIMD by decomposition of precursor molecules, is that allows a cross-check of the structure of the nascent clusters and simultaneously provide insights into possible amorphous structures that could be present in certain SEI layers.

\section{Materials and Methods \\ Computational and System Details}

The methodology used in this study includes quantum chemistry models and calculations performed with Gaussian09 [59] and GaussView6 for visualization. To obtain the ground state structures geometry optimization and frequency calculations were carried out and the thermodynamic properties were based on the structure obtained after energy minimization. The electrostatic potential obtained from the optimized structures is used to determine the most preferred growth location for a molecule or atom adding into the nucleating SEI. The B3PW91 hybrid exchange-correlation functional that was successfully applied to many chemistries $[25,60-62]$ was used along with the $6-311++G(d, p)$ basis set for geometry optimization and evaluation of the molecular orbitals for $\mathrm{LiOH}$ and $\mathrm{Li}_{2} \mathrm{O}$ models. For the cluster calculations, we use an implicit solvent Tetrahydrofuran (THF) with a value of 7.2 for the dielectric constant to emulate 1,2-dimethoxyethane (DME). This implicit solvent model approximates the surrounding electrolyte environment. The implicit solvation is implemented via the Polarizable Continuum Model and the IEFPCM integral equation formalism $[63,64]$ that follows a self-consistent reactive field technique.

The Vienna ab initio Simulation Package (VASP) [65-67] was employed to study the behavior of SEI nucleation on a slightly larger scale, taking advantage of the periodic boundary conditions to represent an infinite surface. Projector augmented wave (PAW) pseudopotentials from the VASP database were used to describe electron-ion interactions [68,69]. As exchange-correlation functional, we employed the Perdew-BurkeErnzerhof generalized gradient approximation (GGA-PBE) [70]. The optimized energy cut-off for the plane-wave basis expansion was $400 \mathrm{eV}$. The ions were relaxed to their ground state via a conjugate-gradient technique. A width of $0.1 \mathrm{eV}$ was used for Gaussian smearing. A $2 \times 2 \times 1$ k-point Monkhorst-Pack [71] mesh was employed for dynamics calculations. For electronic self-consistent iteration and forces ionic relaxation, the convergence criteria were set to $10^{-4}$ and $0.02 \mathrm{eV}$, respectively. To study the nucleation of $\mathrm{LiOH}$ and $\mathrm{Li}_{2} \mathrm{O}$ by reaction of precursors (water and $\mathrm{O}_{2}$ ) on a $\mathrm{Li}$ surface, AIMD simulations were used. A canonical NVT ensemble was used with a Nose thermostat [72,73], the initial temperature of the simulation is $330 \mathrm{~K}$, and a progressive cooling is performed by lowering the temperature $10 \mathrm{~K}$ every 5 ps until a final temperature of $270 \mathrm{~K}$ is achieved using a time step of 1 femtosecond with a damping parameter of 0.5.

\section{Conclusions}

In this paper, we studied the possible nucleation and initial growth mechanisms for the SEI components $\mathrm{Li}_{2} \mathrm{O}$ and $\mathrm{LiOH}$. Our approach assumes that a $\mathrm{Li}$ metal cluster represents a portion of the surface where inhomogeneous plating is taking place. This allows the study of SEI structures in lithium-rich environments simulating the initial stages of 
electrolyte decomposition and SEI formation. An additional model is studied in which already formed fragments of SEI in the electrolyte-electrode interface are joined together to form larger SEI clusters. We use ab initio methods in cluster calculations to determine the preferential addition sites for $\mathrm{OH}$ or $\mathrm{O}$ radicals, and the structures are compared to those induced by precursors on Li metal slabs, as obtained in the AIMD simulations. Studying the nucleation mechanism of different SEI components allows for an improved fundamental understanding of the SEI properties and a prediction of the possible SEI structures that the SEI components may have, as these reactions continue during battery cycling. The ability to characterize SEI structures and growing morphologies, along with their chemical characteristics, is crucial to understand ionic and electronic transport through the SEI. Moreover, the research presented here provides thermodynamics and kinetics of nucleation and growth that are useful for the development of coarse-grained models (for example, Kinetic Monte Carlo) and also for force field development for classical molecular dynamics simulations. In addition, a crucial need in battery research is the understanding of ion transport through SEI layers, using methods such as constrained-molecular dynamics [74,75] that require knowledge of the detailed structure and morphology of the growing phase as shown in this work.

In summary, some of the emerging patterns of the SEI growth include the highly symmetrical and crystalline bilayer of $\mathrm{LiOH}$ if a molecular addition mechanism happens. Differently, $\mathrm{OH}$ fragments interact with the Li metal atoms located in a triangular pyramidal geometry with the $\mathrm{OH}$ at the top being equally distant of all three $\mathrm{Li}$ atoms, forming a triangular structure. The calculated $\mathrm{Li}_{2} \mathrm{O}$ SEI nanocluster reveals similarities with the crystalline structure of the $\mathrm{Li}_{2} \mathrm{O}(110)$ facet, and the initial $\mathrm{Li}$ metal cluster becomes completely modified in the sequential addition of Oxygen atoms. However, if partial oxidation of a Li metal cluster happens, the SEI will nucleate in one site of the Li metal creating pure $\mathrm{Li}_{2} \mathrm{O}$ before oxidizing any other part of the metal cluster. In a larger system such as the one shown in Figure $8 \mathrm{c}$, the $\mathrm{Li}_{2} \mathrm{O}$ starts to form an antifluorite structure characterized by Lithium located at the tetrahedral interstitial sites surrounded by Oxygen. However, in smaller clusters, the $\mathrm{O}$ atoms are located in the tetrahedral site (Figure 7) or in the middle of three Lithium atoms resembling a tri-capped trigonal prismatic coordination, a structure usually found at higher pressure [76].

The study of the possible mechanisms of SEI nucleation and growth is of great importance towards the elucidation of the SEI structure and the Li cation deposition and reduction sites and to provide the basic understanding of the structure of the nucleating SEI. The analysis of the electrostatic potential surfaces allows a preliminary discussion on possible cationic migration patterns through the SEI.

Supplementary Materials: The following are available online at https://www.mdpi.com/article/10.3 390/batteries7040073/s1, Figure S1: Relative Gibbs Free Energy of Formation for LiOH fragmental growth mechanism; Figure S2: Radial distribution function comparison of the crystalline structure of $\mathrm{LiOH}$ and LiOH AIMD structure after cooling; Figure S3: Optimized SEI nanoclusters (1 to 3 Oxygen additions) of $\mathrm{Li}_{2} \mathrm{O}$ structure and corresponding ESP; Figure S4: Radial distribution function comparison of $\mathrm{Li}_{2} \mathrm{O}$ crystalline structure and $\mathrm{Li}_{2} \mathrm{O}$ AIMD structure after cooling.

Author Contributions: S.A.-G. and P.B.B. conceptualized the idea; S.A.-G. performed the simulations and wrote the manuscript; S.A.-G. and P.B.B. analyzed the results; P.B.B. supervised the work. All authors have read and agreed to the published version of the manuscript.

Funding: This work was supported by the U.S. Department of Energy's Office of Energy Efficiency and Renewable Energy (EERE), as part of the Battery 500 Consortium, Award Number DE-EE0008210.

Institutional Review Board Statement: Not applicable.

Informed Consent Statement: Not applicable.

Data Availability Statement: The data presented in this study are available on request from the corresponding author. 
Acknowledgments: Supercomputer resources from the Texas A\&M University High Performance Computer Center and Texas Advanced Computing Center (TACC) are gratefully acknowledged.

Conflicts of Interest: The authors declare no conflict of interest.

\section{References}

1. Fang, C.; Wang, X.; Meng, Y.S. Key Issues Hindering a Practical Lithium-Metal Anode. Trends Chem. 2019, 1, 152-158. [CrossRef]

2. Goodenough, J.B.; Kim, Y. Challenges for Rechargeable Li Batteries. Chem. Mater. 2010, 22, 587-603. [CrossRef]

3. Chen, X.; Hou, T.; Persson, K.A.; Zhang, Q. Combining theory and experiment in lithium-sulfur batteries: Current progress and future perspectives. Mater. Today 2019, 22, 142-158. [CrossRef]

4. Fu, K.; Gong, Y.; Hitz, G.T.; McOwen, D.W.; Li, Y.; Xu, S.; Wen, Y.; Zhang, L.; Wang, C.; Pastel, G.; et al. Three-dimensional bilayer garnet solid electrolyte based high energy density lithium metal-sulfur batteries. Energy Environ. Sci. 2017, 10, 1568-1575. [CrossRef]

5. Lai, J.; Xing, Y.; Chen, N.; Li, L.; Wu, F.; Chen, R. Electrolytes for Rechargeable Lithium-Air Batteries. Angew. Chem. Int. Ed. 2020, 59, 2974-2997. [CrossRef] [PubMed]

6. Lin, D.; Liu, Y.; Cui, Y. Reviving the lithium metal anode for high-energy batteries. Nat. Nanotechnol. 2017, 12, 194. [CrossRef]

7. Fan, L.; Zhuang, H.L.; Zhang, W.; Fu, Y.; Liao, Z.; Lu, Y. Stable Lithium Electrodeposition at Ultra-High Current Densities Enabled by 3D PMF/Li Composite Anode. Adv. Energy Mater. 2018, 8, 1703360. [CrossRef]

8. Ding, F.; Xu, W.; Graff, G.L.; Zhang, J.; Sushko, M.L.; Chen, X.; Shao, Y.; Engelhard, M.H.; Nie, Z.; Xiao, J.; et al. Dendrite-Free Lithium Deposition via Self-Healing Electrostatic Shield Mechanism. J. Am. Chem. Soc. 2013, 135, 4450-4456. [CrossRef]

9. Li, W.; Yao, H.; Yan, K.; Zheng, G.; Liang, Z.; Chiang, Y.-M.; Cui, Y. The synergetic effect of lithium polysulfide and lithium nitrate to prevent lithium dendrite growth. Nat. Commun. 2015, 6, 7436. [CrossRef]

10. Lu, Y.; Tu, Z.; Archer, L.A. Stable lithium electrodeposition in liquid and nanoporous solid electrolytes. Nat. Mater. 2014, 13, 961-969. [CrossRef]

11. Zheng, G.; Lee, S.W.; Liang, Z.; Lee, H.-W.; Yan, K.; Yao, H.; Wang, H.; Li, W.; Chu, S.; Cui, Y. Interconnected hollow carbon nanospheres for stable lithium metal anodes. Nat. Nanotechnol. 2014, 9, 618-623. [CrossRef] [PubMed]

12. Aurbach, D.; Zinigrad, E.; Teller, H.; Dan, P. Factors which limit the cycle life of rechargeable lithium (metal) batteries. J. Electrochem. Soc. 2000, 147, 1274-1279. [CrossRef]

13. Qian, J.; Henderson, W.A.; Xu, W.; Bhattacharya, P.; Engelhard, M.; Borodin, O.; Zhang, J.G. High rate and stable cycling of lithium metal anode. Nat. Commun. 2015, 6, 6362. [CrossRef] [PubMed]

14. Suo, L.; Hu, Y.-S.; Li, H.; Armand, M.; Chen, L. A new class of Solvent-in-Salt electrolyte for high-energy rechargeable metallic lithium batteries. Nat. Commun. 2013, 4, 1481. [CrossRef]

15. Ryou, M.-H.; Lee, Y.M.; Lee, Y.; Winter, M.; Bieker, P. Mechanical Surface Modification of Lithium Metal: Towards Improved Li Metal Anode Performance by Directed Li Plating. Adv. Funct. Mater. 2015, 25, 834-841. [CrossRef]

16. Bai, P.; Li, J.; Brushett, F.R.; Bazant, M.Z. Transition of lithium growth mechanisms in liquid electrolytes. Energy Environ. Sci. 2016, 9, 3221-3229. [CrossRef]

17. Biswal, P.; Stalin, S.; Kludze, A.; Choudhury, S.; Archer, L.A. Nucleation and Early Stage Growth of Li Electrodeposits. Nano Lett. 2019, 19, 8191-8200. [CrossRef]

18. Peled, E. The Electrochemical Behavior of Alkali and Alkaline Earth Metals in Nonaqueous Battery Systems-The Solid Electrolyte Interphase Model. J. Electrochem. Soc. 1979, 126, 2047. [CrossRef]

19. Peled, E.; Menkin, S. Review-SEI: Past, Present and Future. J. Electrochem. Soc. 2017, 164, A1703-A1719. [CrossRef]

20. Kamphaus, E.P.; Angarita-Gomez, S.; Qin, X.; Shao, M.; Engelhard, M.; Mueller, K.T.; Murugesan, V.; Balbuena, P.B. Role of Inorganic Surface Layer on Solid Electrolyte Interphase Evolution at Li-Metal Anodes. ACS Appl. Mater. Interfaces 2019, 11, 31467-31476. [CrossRef]

21. Cheng, X.-B.; Zhang, R.; Zhao, C.-Z.; Wei, F.; Zhang, J.-G.; Zhang, Q. A Review of Solid Electrolyte Interphases on Lithium Metal Anode. Adv. Sci. 2016, 3, 1500213. [CrossRef] [PubMed]

22. Li, T.; Zhang, X.-Q.; Shi, P.; Zhang, Q. Fluorinated Solid-Electrolyte Interphase in High-Voltage Lithium Metal Batteries. Joule 2019, 3, 2647-2661. [CrossRef]

23. Wang, X.; Tan, Y.; Shen, G.; Zhang, S. Recent progress in fluorinated electrolytes for improving the performance of Li-S batteries. J. Energy Chem. 2020, 41, 149-170. [CrossRef]

24. von Aspern, N.; Röschenthaler, G.V.; Winter, M.; Cekic-Laskovic, I. Fluorine and Lithium: Ideal Partners for High-Performance Rechargeable Battery Electrolytes. Angew. Chem. Int. Ed. 2019, 58, 15978-16000. [CrossRef]

25. Camacho-Forero, L.E.; Smith, T.W.; Bertolini, S.; Balbuena, P.B. Reactivity at the Lithium-Metal Anode Surface of Lithium-Sulfur Batteries. J. Phys. Chem. C 2015, 119, 26828-26839. [CrossRef]

26. Zhang, W.-J. A review of the electrochemical performance of alloy anodes for lithium-ion batteries. J. Power Sources 2011, 196, 13-24. [CrossRef]

27. Etacheri, V.; Haik, O.; Goffer, Y.; Roberts, G.A.; Stefan, I.C.; Fasching, R.; Aurbach, D. Effect of Fluoroethylene Carbonate (FEC) on the Performance and Surface Chemistry of Si-Nanowire Li-Ion Battery Anodes. Langmuir 2012, 28, 965-976. [CrossRef] [PubMed]

28. Verma, P.; Maire, P.; Novák, P. A review of the features and analyses of the solid electrolyte interphase in Li-ion batteries. Electrochim. Acta 2010, 55, 6332-6341. [CrossRef] 
29. Martinez de la Hoz, J.M.; Leung, K.; Balbuena, P.B. Reduction Mechanisms of Ethylene Carbonate on Si Anodes of Lithium-Ion Batteries: Effects of Degree of Lithiation and Nature of Exposed Surface. ACS Appl. Mater. Interfaces 2013, 5, 13457-13465. [CrossRef]

30. Ganesh, P.; Kent, P.R.C.; Jiang, D.-E. Solid-Electrolyte Interphase Formation and Electrolyte Reduction at Li-Ion Battery Graphite Anodes: Insights from First-Principles Molecular Dynamics. J. Phys. Chem. C 2012, 116, 24476-24481. [CrossRef]

31. Odziemkowski, M.; Irish, D.E. An Electrochemical Study of the Reactivity at the Lithium Electrolyte/Bare Lithium Metal Interface: I. Purified Electrolytes. J. Electrochem. Soc. 1992, 139, 3063-3074. [CrossRef]

32. Peled, E.; Golodnitsky, D.; Ardel, G. Advanced model for solid electrolyte interphase electrodes in liquid and polymer electrolytes. J. Electrochem. Soc. 1997, 144, L208-L210. [CrossRef]

33. Ein-Eli, Y. A New Perspective on the Formation and Structure of the Solid Electrolyte Interface at the Graphite Anode of Li-Ion Cells. Electrochem. Solid-State Lett. 1999, 2, 212. [CrossRef]

34. Leung, K. DFT modelling of explicit solid-solid interfaces in batteries: Methods and challenges. Phys. Chem. Chem. Phys. 2020, 22, 10412-10425. [CrossRef]

35. Lee, J.-I.; Song, G.; Cho, S.; Han, D.-Y.; Park, S. Lithium Metal Interface Modification for High-Energy Batteries: Approaches and Characterization. Batter. Supercaps 2020, 3, 828-859. [CrossRef]

36. Liu, L.; Zhu, M. Modeling of SEI Layer Growth and Electrochemical Impedance Spectroscopy Response using a ThermalElectrochemical Model of Li-ion Batteries. ECS Trans. 2014, 61, 43-61. [CrossRef]

37. Liu, C.; Gao, Y.; Liu, L. Toward safe and rapid battery charging: Design optimal fast charging strategies thorough a physics-based model considering lithium plating. Int. J. Energy Res. 2021, 45, 2303-2320. [CrossRef]

38. Kamphaus, E.P.; Gomez, S.A.; Qin, X.; Shao, M.; Balbuena, P.B. Effects of Solid Electrolyte Interphase Components on the Reduction of LiFSI over Lithium Metal. ChemPhysChem 2020, 21, 1310-1317. [CrossRef] [PubMed]

39. Kamphaus, E.P.; Balbuena, P.B. Polysulfide reduction and Li2S phase formation in the presence of lithium metal and solid electrolyte interphase layer. J. Power Sources 2021, 485, 229289. [CrossRef]

40. Liu, J.; Bao, Z.; Cui, Y.; Dufek, E.J.; Goodenough, J.B.; Khalifah, P.; Li, Q.; Liaw, B.Y.; Liu, P.; Manthiram, A.; et al. Pathways for practical high-energy long-cycling lithium metal batteries. Nat. Energy 2019, 4, 180-186. [CrossRef]

41. Suo, L.; Oh, D.; Lin, Y.; Zhuo, Z.; Borodin, O.; Gao, T.; Wang, F.; Kushima, A.; Wang, Z.; Kim, H.-C.; et al. How Solid-Electrolyte Interphase Forms in Aqueous Electrolytes. J. Am. Chem. Soc. 2017, 139, 18670-18680. [CrossRef]

42. Tan, J.; Matz, J.; Dong, P.; Shen, J.; Ye, M. A Growing Appreciation for the Role of LiF in the Solid Electrolyte Interphase. Adv. Energy Mater. 2021, 11, 2100046. [CrossRef]

43. Hsieh, Y.-C.; Thienenkamp, J.H.; Huang, C.-J.; Tao, H.-C.; Rodehorst, U.; Hwang, B.J.; Winter, M.; Brunklaus, G. Revealing the Impact of Film-Forming Electrolyte Additives on Lithium Metal Batteries via Solid-State NMR/MRI Analysis. J. Phys. Chem. C 2021, 125, 252-265. [CrossRef]

44. Otto, S.-K.; Moryson, Y.; Krauskopf, T.; Peppler, K.; Sann, J.; Janek, J.; Henss, A. In-Depth Characterization of Lithium-Metal Surfaces with XPS and ToF-SIMS: Toward Better Understanding of the Passivation Layer. Chem. Mater. 2021, 33, 859-867. [CrossRef]

45. Liu, W.; Liu, P.; Mitlin, D. Review of Emerging Concepts in SEI Analysis and Artificial SEI Membranes for Lithium, Sodium, and Potassium Metal Battery Anodes. Adv. Energy Mater. 2020, 10, 2002297. [CrossRef]

46. Guo, R.; Wang, D.; Zuin, L.; Gallant, B.M. Reactivity and Evolution of Ionic Phases in the Lithium Solid-Electrolyte Interphase. ACS Energy Lett. 2021, 6, 877-885. [CrossRef]

47. Liu, L.; Guan, P. Phase-Field Modeling of Solid Electrolyte Interphase (SEI) Evolution: Considering Cracking and Dissolution during Battery Cycling. ECS Trans. 2019, 89, 101-111. [CrossRef]

48. Mu, W.; Liu, X.; Wen, Z.; Liu, L. Numerical simulation of the factors affecting the growth of lithium dendrites. J. Energy Storage 2019, 26, 100921. [CrossRef]

49. Vu, T.T.; Eom, G.H.; Lee, J.; Park, M.-S.; Moon, J. Electrolyte interface design for regulating Li dendrite growth in rechargeable Li-metal batteries: A theoretical study. J. Power Sources 2021, 496, 229791. [CrossRef]

50. Dong, K.; Xu, Y.; Tan, J.; Osenberg, M.; Sun, F.; Kochovski, Z.; Pham, D.T.; Mei, S.; Hilger, A.; Ryan, E.; et al. Unravelling the Mechanism of Lithium Nucleation and Growth and the Interaction with the Solid Electrolyte Interface. ACS Energy Lett. 2021, 6, 1719-1728. [CrossRef]

51. Hope, M.A.; Rinkel, B.L.D.; Gunnarsdóttir, A.B.; Märker, K.; Menkin, S.; Paul, S.; Sergeyev, I.V.; Grey, C.P. Selective NMR observation of the SEI-metal interface by dynamic nuclear polarisation from lithium metal. Nat. Commun. 2020, $11,2224$. [CrossRef]

52. Jiang, C.; Ma, C.; Yang, F.; Cai, X.; Liu, Y.; Tao, X. Materials chemistry among the artificial solid electrolyte interphase of metallic lithium anode. Mater. Chem. Front. 2021, 5, 5194-5210. [CrossRef]

53. Shadike, Z.; Lee, H.; Borodin, O.; Cao, X.; Fan, X.; Wang, X.; Lin, R.; Bak, S.-M.; Ghose, S.; Xu, K.; et al. Identification of LiH and nanocrystalline LiF in the solid-electrolyte interphase of lithium metal anodes. Nat. Nanotechnol. 2021, 16, 549-554. [CrossRef] [PubMed]

54. Li, Y.; Huang, W.; Li, Y.; Pei, A.; Boyle, D.T.; Cui, Y. Correlating Structure and Function of Battery Interphases at Atomic Resolution Using Cryoelectron Microscopy. Joule 2018, 2, 2167-2177. [CrossRef] 
55. Hehre, W.J.; Radom, L.; Schleyer, P.V.R.; Pople, J.A. Ab Initio Molecular Orbital Theory; John Wiley \& Sons: New York, NY, USA, 1986.

56. Dubouis, N.; Lemaire, P.; Mirvaux, B.; Salager, E.; Deschamps, M.; Grimaud, A. The role of the hydrogen evolution reaction in the solid-electrolyte interphase formation mechanism for "Water-in-Salt" electrolytes. Energy Environ. Sci. 2018, 11, 3491-3499. [CrossRef]

57. Kamphaus, E.P.; Hight, K.; Dermott, M.; Balbuena, P.B. Model systems for screening and investigation of lithium metal electrode chemistry and dendrite formation. Phys. Chem. Chem. Phys. 2020, 22, 575-588. [CrossRef]

58. Hermann, A.; Ashcroft, N.; Hoffmann, R. Lithium hydroxide, LiOH, at elevated densities. J. Chem. Phys. 2014, 141, 024505. [CrossRef]

59. Frisch, M.J.; Trucks, G.W.; Schlegel, H.B.; Scuseria, G.E.; Robb, M.A.; Cheeseman, J.R.; Scalmani, G.; Barone, V.; Mennucci, B.; Petersson, G.A.; et al. Gaussian 09, rev. D. 01; Gaussian, Inc.: Wallingfort, CT, USA, 2009. Available online: https://gaussian.com/ glossary /g09/ (accessed on 28 October 2021).

60. Jung, H.M.; Park, S.-H.; Jeon, J.; Choi, Y.; Yoon, S.; Cho, J.-J.; Oh, S.; Kang, S.; Han, Y.-K.; Lee, H. Fluoropropane sultone as an SEI-forming additive that outperforms vinylene carbonate. J. Mater. Chem. A 2013, 1, 11975-11981. [CrossRef]

61. Jalbout, A.F.; Nazari, F.; Turker, L. Gaussian-based computations in molecular science. J. Mol. Struct. THEOCHEM 2004, 671, 1-21. [CrossRef]

62. Curtiss, L.A.; Redfern, P.C.; Raghavachari, K.; Pople, J.A. Assessment of Gaussian-2 and density functional theories for the computation of ionization potentials and electron affinities. J. Chem. Phys. 1998, 109, 42-55. [CrossRef]

63. Tomasi, J.; Mennucci, B.; Cammi, R. Quantum Mechanical Continuum Solvation Models. Chem. Rev. 2005, 105, 2999-3094. [CrossRef]

64. Pascual-ahuir, J.L.; Silla, E.; Tuñon, I. GEPOL: An improved description of molecular surfaces. III. A new algorithm for the computation of a solvent-excluding surface. J. Comput. Chem. 1994, 15, 1127-1138. [CrossRef]

65. Kresse, G.; Furthmuller, J. Efficiency of ab-initio total energy calculations for metals and semiconductors using a plane-wave basis set. Comput. Mater. Sci. 1996, 6, 15-50. [CrossRef]

66. Kresse, G.; Hafner, J. Ab initio molecular dynamics for liquid metals. Phys. Rev. B 1993, 47, 558. [CrossRef]

67. Kresse, G.; Hafner, J. Ab initio molecular-dynamics simulation of the liquid-metal-amorphous-semiconductor transition in germanium. Phys. Rev. B 1994, 49, 14251-14269. [CrossRef]

68. Blöchl, P.E. Projector augmented-wave method. Phys. Rev. B 1994, 50, 17953. [CrossRef] [PubMed]

69. Kresse, G.; Joubert, D. From ultrasoft pseudopotentials to the projector augmented-wave method. Phys. Rev. B 1999, 59, 1758-1775. [CrossRef]

70. Perdew, J.P.; Burke, K.; Ernzerhof, M. Generalized Gradient Approximation Made Simple. Phys. Rev. Lett. 1996, 77, 3865-3868. [CrossRef] [PubMed]

71. Monkhorst, H.J.; Pack, J.D. Special points for Brillouin-zone integrations. Phys. Rev. B 1976, 13, 5188-5192. [CrossRef]

72. Nosé, S. A unified formulation of the constant temperature molecular dynamics methods. J. Chem. Phys. 1984, 81, 511-519. [CrossRef]

73. Hoover, W.G. Canonical dynamics: Equilibrium phase-space distributions. Phys. Rev. A 1985, 31, 1695-1697. [CrossRef] [PubMed]

74. Angarita-Gomez, S.; Balbuena, P.B. Insights into lithium ion deposition on lithium metal surfaces. Phys. Chem. Chem. Phys. 2020, 22, 21369-21382. [CrossRef] [PubMed]

75. Angarita-Gomez, S.; Balbuena, P.B. Solvation vs. Surface Charge Transfer: An Interfacial Chemistry Game Drives Cation Motion. Chem. Commun. 2021, 57, 6189-6192. [CrossRef] [PubMed]

76. Lazicki, A.; Yoo, C.S.; Evans, W.J.; Pickett, W.E. Pressure-induced antifluorite-to-anticotunnite phase transition in lithium oxide. Phys. Rev. B 2006, 73, 184120. [CrossRef] 